\title{
Perbedaan profil lipid pada remaja obes dan tidak obes di Kecamatan Bolangitang Barat
}

\author{
${ }^{1}$ Hendry J. R. Tandra \\ ${ }^{2}$ Widhi Bodhi \\ ${ }^{3}$ Billy J. Kepel
}

\author{
${ }^{1}$ Kandidat Skripsi Fakultas Kedokteran Universitas Sam Ratulangi Manado \\ ${ }^{2}$ Bagian Kimia Fakultas Kedokteran Universitas Sam Ratulangi Manado \\ Email: inal_rooney@yahoo.com
}

\begin{abstract}
Obesity might cause dyslipidemia, marked by increased cholesterol, triglycerides, and LDL levels, as well as reduced HDL level. Dyslipidemia is related to atherosclerosis that can result in cardiovascular diseases. This study was aimed to identify differences of lipid profiles in obese and non-obese teenagers at West Bolangitang, North Bolaang Mongondow. This was an observational analytical study with a cross sectional design conducted from October to November 2016. Subjects were 60 teenagers obtained by using consecutive sampling method and were divided into two groups: obese (29 teenagers) and non-obese (31 teenagers). Lipid profile examinations were performed on all of them. Statistical analysis of total cholesterol level of the two groups used independent $t$ test $(\mathrm{p}=0.002)$ dan Pearson correlation test $(\mathrm{p}=0.028)$. The normality test of triglyseride level showed that data were not normally distributed, therefore, the analysis was continued with Mann-Whitney test $(\mathrm{p}=0.328)$ and Spearman correlation test $(\mathrm{p}=0.542)$. The normality test of LDL level showed that data were not normally distributed, therefore, the analysis was continued with Mann-Whitney test $(\mathrm{p}=0.004)$ and Spearman correlation test $(\mathrm{p}=0.032)$. The normality test of HDL level showed that data were not normally distributed, therefore, the analysis was continued with Mann-Whitney test $(\mathrm{p}=0.063)$ and Spearman correlation test $(\mathrm{p}=0.054)$. Conclusion: There were significant differences of total cholesterol and LDL levels but there were no significant differences of triglyceride and HDL levels between obese teenagers and non-obese teenagers.
\end{abstract}

Keywords: lipid profile, adolescents, obesity.

\begin{abstract}
Abstrak: Obesitas dapat menyebabkan peningkatan lipid kolesterol, trigliserida, maupun LDL dan penurunan lipid HDL yang disebut dislipidemia. Dislipidemia berhubungan erat dengan terjadinya aterosklerosis yang dapat menimbulkan penyakit kardiovaskular. Penelitian ini bertujuan untuk mengetahui perbedaan profil lipid pada remaja obes dan remaja tidak obes di Kecamatan Bolangitang Barat, Kabupaten Bolaang Mongondow Utara. Jenis penelitian ialah observasional analitik dengan desain potong lintang. Penelitian dilaksanakan pada bulan Oktober dan November 2016 dengan sampel penelitian berjumlah 60 remaja terdiri dari kelompok remaja obes ( 29 orang) dan kelompok remaja tidak obes (31 orang) yang diperoleh dengan metode consecutive sampling. Pemeriksaan profil lipid dilakukan pada semua remaja. Uji statistik terhadap kadar kolesterol total antara kedua kelompok menggunakan uji independent $t$ test $(\mathrm{p}=0,002)$ dan uji Pearson correlation $(\mathrm{p}=0,028)$. Uji normalitas terhadap kadar trigliserida mendapatkan data tidak terdistribusi normal sehingga dilanjutkan dengan uji Mann-Whitney $(p=0,328)$ dan uji korelasi Spearman $(p=0,542)$. Uji normalitas terhadap kadar LDL mendapatkan data tidak terdistribusi normal sehingga dilanjutkan dengan uji Mann-Whitney $(p=0,004)$ dan uji korelasi Spearman $(p=0,032)$. Uji normalitas terhadap kadar HDL mendapatkan data tidak terdistribusi normal sehingga dilanjutkan dengan uji Mann-Whitney $(\mathrm{p}=0,063)$ dan uji korelasi Spearman $(\mathrm{p}=0,054)$. Simpulan: Terdapat perbedaan bermakna dalam hal kadar kolesterol total dan LDL, tetapi tidak terdapat perbedaan bermakna dalam hal kadar trigliserida dan HDL antara remaja obes dan tidak obes.
\end{abstract}

Kata kunci: profil lipid, remaja, obesitas 
Dewasa ini obesitas telah menjadi salah satu masalah utama kesehatan dunia. Obesitas dapat didefiniskan sebagai suatu abnormalitas atau kelebihan akumulasi lemak yang berisiko terhadap kesehatan. Obesitas ditentukan dengan pengukuran indek massa tubuh (IMT) dan lingkar pinggang. ${ }^{1}$ Diperkirakan lebih dari sepertiga $(35,7 \%)$ orang dewasa menyandang obesitas. $^{2}$ Kurang lebih 2,8 juta penduduk dunia meninggal tiap tahun akibat obesitas. ${ }^{3}$

Menurut Riset Kesehatan Dasar (Riskesdas) Indonesia tahun 2013, prevalensi obesitas pada penduduk laki-laki dewasa sebanyak 19,7\%, meningkat dibanding tahun $2007(13,9 \%)$ dan tahun 2010 (7,8\%). Prevalensi terendah di Nusa Tenggara Timur $(9,8 \%)$ dan tertinggi di Sulawesi Utara (34,7\%). Pada tahun 2013, prevalensi obesitas pada penduduk perempuan dewasa sebanyak $32,9 \%$, lebih tinggi dari tahun 2007 (13,9\%) dan tahun $2010(15,5 \%)$. Prevalensi terendah di Nusa Tenggara Timur $(5,6 \%)$ dan tertinggi di Sulawesi Utara $(49,5 \%) .{ }^{4}$ Di Sulawesi Utara sendiri dilakukan survei pada salah satu SMK di Tondano dan didapatkan hasil $4,30 \%$ remaja laki-laki dan $22,03 \%$ remaja perempuan mengalami obesitas. ${ }^{5}$

Obesitas pada remaja berisiko menjadi obesitas pada saat usia dewasa dan meningkatkan risiko terkena penyakit kardiovaskuler dan metabolik. ${ }^{3,6}$ Ukuran antoprometri dan derajat obesitas juga berkaitan dengan kadar lipid darah yang dapat menyebabkan dislipidemia dan berhubungan erat dengan peningkatan tekanan darah dan kadar insulin. ${ }^{7}$ Peningkatan lipid kolesterol, trigliserida, maupun low density lipoprotein (LDL) dapat terjadi pada obesitas.

Dislipidemia adalah kelainan metabolisme lipid yang ditandai dengan peningkatan atau penurunan fraksi lipid plasma darah. Kelainan fraksi lipid yang paling utama ialah kenaikan kadar kolesterol total $(\geq 200 \mathrm{mg} / \mathrm{dl})$, kolesterol LDL $(\geq 100 \mathrm{mg} / \mathrm{dl})$, kenaikan kadar trigliserida $(\geq 150 \mathrm{mg} / \mathrm{dl})$ serta penurunan kadar high density lipoprotein (HDL) $(<40$ mg/dl). ${ }^{9}$ Dislipidemia berhubungan erat dengan terjadinya aterosklerosis yang dapat menimbulkan penyakit kadriovaskular. ${ }^{10}$

Berdasarkan Riset Kesehatan Dasar (Riskesdas) Indonesia tahun 2013, proporsi kolesterol total penduduk $\geq 15$ tahun di atas nilai normal sebesar 35,9\%; kadar HDL di bawah nilai normal sebesar 22,9\%; kadar LDL di atas nilai normal sebesar 76,2\%; dan kadar trigliserida di atas nilai normal sebesar $24,9 \%$. $^{4}$

Penelitian sebelumnya di Bitung pada siswa obes menunjukkan peningkatan kadar kolesterol total ( $\geq 200 \mathrm{mg} / \mathrm{dL})$ sebesar 26\%; kadar HDL di bawah nilai normal ( $<40 \mathrm{mg} / \mathrm{dL}$ untuk laki-laki, $<50 \mathrm{mg} / \mathrm{dL}$ untuk perempuan) sebesar $62 \%$; peningkatan kadar LDL di atas nilai normal $(\geq 100 \mathrm{mg} / \mathrm{dL}) \quad$ sebesar $82 \%$; dan peningkatan kadar trigliserida di atas nilai normal $(\geq 150 \mathrm{mg} / \mathrm{dL})$ sebesar $12 \%{ }^{11}$

Penelitian ini bertujuan untuk mengetahui perbedaan kadar profil lipid pada remaja obes dan remaja tidak obes di Kecamatan Bolangitang Barat, Kabupaten Bolaang Mongondow Utara

\section{METODE PENELITIAN}

Jenis penelitian ini ialah analitik observasional dengan desain potong lintang pada bulan Oktober 2016 sampai November 2016. Populasi penelitian ini yaitu siswa-siswi SMP dan SMA di Kecamatan Bolangitang Barat. Subjek penelitian ialah siswa-siswi SMP Negeri 1 Bolangitang, SMA Negeri 1 Bolangitang, dan Madrasah Tsanawiyah (MTs) Jambusarang yang terdiri dari 29 remaja obes dan 31 remaja tidak obes, diperoleh dengan metode consecutive sampling. Profil lipid diperiksa di Laboratorium Dinas Kesehatan Provinsi Sulawesi Utara. Data dianalisis dengan SPSS dan nilai $p$ $<0,05$ secara statistik memiliki hubungan bermakna.

\section{HASIL PENELITIAN}

Subjek penelitian ini berjumlah 60 orang dengan 29 remaja obes yang terdiri dari 10 orang laki-laki (17\%) dan 19 orang perempuan (31\%); dan 31 remaja tidak 
obes yang terdiri dari 6 orang laki-laki (10\%) dan 25 orang perempuan (42\%).

Tabel 1. Distribusi berdasarkan jenis kelamin

\begin{tabular}{ccccccc}
\hline & \multicolumn{3}{c}{ Jenis kelamin } & \multicolumn{2}{c}{ Total } \\
Variabel & \multicolumn{2}{c}{ Laki-laki } & \multicolumn{2}{c}{ Perempuan } & \multicolumn{2}{c}{ N } \\
& $\mathrm{N}$ & $\%$ & $\mathrm{n}$ & $\%$ & & \\
\hline Obes & 10 & 17 & 19 & 31 & 29 & 48 \\
Tidak & 6 & 10 & 25 & 42 & 31 & 52 \\
obes & 16 & 27 & 44 & 73 & 60 & 100 \\
Total & 16 &
\end{tabular}

Tabel 2 memperlihatkan pada remaja obes terdapat 4 remaja obes $(7 \%$ dari total remaja obes) yang memiliki kadar kolesterol total abnormal $(\geq 200 \mathrm{mg} / \mathrm{dl})$ dan terdapat 25 remaja obes $(42 \%$ dari total remaja obes) yang memiliki kadar kolesterol total normal $(<200 \mathrm{mg} / \mathrm{dl})$. Ke 31 remaja tidak obes $(51 \%)$ memiliki kadar kolesterol total yang normal.

Uji kadar kolesterol total antara kedua kelompok menggunakan independent $t$ test $(\mathrm{p}=0,002)$ dan uji korelasi Pearson $(\mathrm{p}=0,028)($ Tabel 3). Hasil ini menunjukkan terdapat perbedaan bermakna antara kadar kolesterol total pada remaja obes dan remaja tidak obes; juga didapatkan hubungan bermakna antara kadar kolesterol total darah dan IMT dengan koefisien korelasi 0,283 yang berarti memiliki hubungan positif lemah.

Tabel 4 menunjukkan 3 remaja obes (5\% dari total remaja obes) memiliki kadar trigliserida abnormal $(\geq 150 \mathrm{mg} / \mathrm{dl})$ dan 26 remaja obes ( $43 \%$ dari total remaja obes) dengan kadar trigliserida normal $(<150$ $\mathrm{mg} / \mathrm{dl})$. Semua remaja tidak obes yang berjumlah 31 orang (52\%) memiliki kadar trigliserida yang normal.
Uji normalitas terhadap kadar trigliserida mendapatkan data tidak terdistribusi normal sehingga dilanjutkan dengan uji Mann-Whitney $(\mathrm{p}=0,328)$ dan juga uji korelasi Spearman $(\mathrm{p}=0,542)$ (Tabel 5). Hasil ini menunjukkan tidak terdapat perbedaan bermakna antara kadar trigliserida pada remaja obes dan remaja tidak obes; juga tidak terdapat hubungan kadar trigliserida dan IMT yang memiliki koefisien korelasi positif sangat lemah.

Dari hasil pada Tabel 6, diperoleh 15 remaja obes ( $25 \%$ dari total remaja obes) memiliki kadar LDL normal $(<100 \mathrm{mg} / \mathrm{dl})$ dan 14 remaja obes (23\% dari total remaja obes) juga dengan kadar LDL abnormal $(\geq 100 \mathrm{mg} / \mathrm{dl})$. Pada remaja tidak obes didapat 5 remaja tidak obes $(8 \%$ dari total remaja tidak obes) dengan kadar LDL abnormal dan 26 remaja tidak obes $(44 \%$ dari total remaja tidak obes) dengan kadar LDL normal.

Uji normalitas terhadap kadar LDL mendapatkan data tidak terdistribusi normal sehingga dilanjutkan dengan uji Mann-Whitney $(\mathrm{p}=0,004)$ dan uji korelasi $(\mathrm{p}=0,032)$ (Tabel 7). Hasil ini menunjukkan terdapat perbedaan bermakna antara kadar LDL pada remaja obes dan remaja tidak obes, dan juga adanya hubungan bermakna antara kadar LDL dan IMT dengan koefisien korelasi 0,277 yang berarti positif lemah.

Pada Tabel 8 dapat dilihat bahwa terdapat 13 remaja obes $(21 \%$ dari total remaja obes) yang memiliki kadar HDL normal (laki-laki $\geq 40 \mathrm{mg} / \mathrm{dl}$, perempuan $\geq 50 \mathrm{mg} / \mathrm{dl}$ ) dan 16 remaja obes lainnya (27\% dari total remaja obes) dengan kadar HDL abnormal (laki-laki $<40 \quad \mathrm{mg} / \mathrm{dl}$, perempuan $<50 \mathrm{mg} / \mathrm{dl}$ ).

Tabel 2. Data kadar kolesterol total dari subjek penelitian

\begin{tabular}{ccccccc}
\hline \multirow{2}{*}{ Variabel } & \multicolumn{7}{c}{ Kolesterol total } \\
\cline { 2 - 7 } & $\begin{array}{c}\text { Normal } \\
(\%)\end{array}$ & $\begin{array}{c}\text { Abnormal } \\
(\%)\end{array}$ & $\begin{array}{c}\text { Minimum } \\
(\mathrm{mg} / \mathrm{dl})\end{array}$ & $\begin{array}{c}\text { Maksimun } \\
(\mathrm{mg} / \mathrm{dl})\end{array}$ & $\begin{array}{c}\text { Mean } \\
(\mathrm{mg} / \mathrm{dl})\end{array}$ & $\begin{array}{c}\text { Standard } \\
\text { Deviasi }\end{array}$ \\
\hline Obes & 86 & 14 & 135 & 215 & 167,17 & 22,779 \\
\hline Tidak obes & 100 & - & 125 & 190 & 150,84 & 15,397 \\
\hline
\end{tabular}


Tabel 3. Analisis statistik kadar kolesterol total

\begin{tabular}{ccc}
\hline Uji statistik & p & r \\
\hline Independent t test & 0,002 & - \\
Pearson Correlation & 0,028 & 0,283 \\
\hline
\end{tabular}

Tabel 4. Data kadar trigliserida dari subjek penelitian

\begin{tabular}{ccccccc}
\hline \multirow{2}{*}{ Variabel } & \multicolumn{6}{c}{ Trigliserida } \\
\cline { 2 - 7 } & $\begin{array}{c}\text { Normal } \\
(\%)\end{array}$ & $\begin{array}{c}\text { Abnormal } \\
(\%)\end{array}$ & $\begin{array}{c}\text { Minimum } \\
(\mathrm{mg} / \mathrm{dl})\end{array}$ & $\begin{array}{c}\text { Maksimun } \\
(\mathrm{mg} / \mathrm{dl})\end{array}$ & $\begin{array}{c}\text { Mean } \\
(\mathrm{mg} / \mathrm{dl})\end{array}$ & $\begin{array}{c}\text { Standard } \\
\text { Deviasi }\end{array}$ \\
\hline Obes & 90 & 10 & 45 & 250 & 95,69 & 43,316 \\
Tidak obes & 100 & - & 45 & 145 & 81,45 & 22,737 \\
\hline
\end{tabular}

Tabel 5. Analisis statistik kadar trigliserida

\begin{tabular}{ccc}
\hline Uji statistik & p & r \\
\hline Mann-Whitney & 0,328 & - \\
Spearman Correlation & 0,542 & 0,080 \\
\hline
\end{tabular}

Tabel 6. Data kadar LDL dari subjek penelitian

\begin{tabular}{ccccccc}
\hline \multirow{2}{*}{ Variabel } & \multicolumn{7}{c}{ LDL } \\
\cline { 2 - 7 } & $\begin{array}{c}\text { Normal } \\
(\%)\end{array}$ & $\begin{array}{c}\text { Abnormal } \\
(\%)\end{array}$ & $\begin{array}{c}\text { Minimum } \\
(\mathrm{mg} / \mathrm{dl})\end{array}$ & $\begin{array}{c}\text { Maksimun } \\
(\mathrm{mg} / \mathrm{dl})\end{array}$ & $\begin{array}{c}\text { Mean } \\
(\mathrm{mg} / \mathrm{dl})\end{array}$ & $\begin{array}{c}\text { Standard } \\
\text { Deviasi }\end{array}$ \\
\hline Obes & 52 & 48 & 69 & 149 & 101,76 & 21,485 \\
\hline Tidak obes & 84 & 16 & 63 & 117 & 86,03 & 14,011 \\
\hline
\end{tabular}

Tabel 7. Analisis statistik kadar LDL

\begin{tabular}{ccc}
\hline Uji Statistik & p & r \\
\hline Mann-Whitney & 0,004 & - \\
Spearman Correlation & 0,032 & 0,277 \\
\hline
\end{tabular}

Tabel 8. Data kadar HDL dari subjek penelitian

\begin{tabular}{ccccccc}
\hline \multirow{2}{*}{ Variabel } & \multicolumn{6}{c}{ HDL } \\
\cline { 2 - 7 } & $\begin{array}{c}\text { Normal } \\
(\%)\end{array}$ & $\begin{array}{c}\text { Abnormal } \\
(\%)\end{array}$ & $\begin{array}{c}\text { Minimum } \\
(\mathrm{mg} / \mathrm{dl})\end{array}$ & $\begin{array}{c}\text { Maksimun } \\
(\mathrm{mg} / \mathrm{dl})\end{array}$ & $\begin{array}{c}\text { Mean } \\
(\mathrm{mg} / \mathrm{dl})\end{array}$ & $\begin{array}{c}\text { Standard } \\
\text { Deviasi }\end{array}$ \\
\hline Obes & 45 & 55 & 38 & 56 & 46,83 & 3,827 \\
\hline Tidak obes & 49 & 51 & 42 & 60 & 48,39 & 3,490 \\
\hline
\end{tabular}

Pada remaja tidak obes diperoleh 15 remaja ( $25 \%$ dari total remaja tidak obes) memiliki kadar HDL normal dan 16 remaja (27\% dari total remaja tidak obes) dengan kadar HDL abnormal.

Uji normalitas terhadap kadar HDL mendapatkan data tidak terdistribusi normal sehingga dilanjutkan dengan uji
Mann-Whitney $(\mathrm{p}=0,063)$ dan uji korelasi $(\mathrm{p}=0,054)$ (Tabel 9) yang menunjukkan tidak terdapat perbedaan bermakna antara kadar HDL pada remaja obes dan remaja tidak obes, serta terdapat hubungan negatif lemah yang tidak bermakna antara kadar HDL dan IMT. 
Tabel 9. Analisis statistik kadar HDL

\begin{tabular}{ccc}
\hline Uji statistik & p & r \\
\hline Mann-Whitney & 0,063 & - \\
Spearman Correlation & 0,054 & $-0,250$ \\
\hline
\end{tabular}

\section{BAHASAN}

Jumlah subjek penelitian yang memenuhi kriteria inklusi pada penelitian ini yaitu 60 orang, dengan 29 remaja obes $(48 \%)$ dan 31 remaja tidak obes $(52 \%)$.

Pada remaja obes jenis kelamin perempuan $(31 \%)$ lebih banyak ditemukan dibandingkan remaja obes laki-laki (17\%). Demikianpula pada remaja tidak obes, jenis kelamin perempuan (42\%) lebih banyak ditemukan daripada laki-laki (10\%). Hal ini disebabkan perempuan cenderung memiliki berat badan lebih (sesuai dengan proporsi lemak tubuh yang lebih) dibandingkan lakilaki, faktor hormonal, dan kurangnya aktivitas fisik. ${ }^{12,13}$ Hasil ini juga sesuai dengan yang ditemukan Tuerah et al. ${ }^{14}$ yang melaporkan prevalensi remaja obes pada perempuan lebih tinggi dibandingkan remaja obes laki-laki.

Dari hasil penelitian didapatkan kadar kolesterol total remaja obes dan tidak obes umumnya berada dalam kisaran normal; hanya terdapat 4 (14\%) dari 29 remaja obes yang memiliki kadar kolesterol total abnormal (hiperkolesterolemia). Hasil penelitian ini hampir sama dengan yang ditemukan oleh Rantung et al. ${ }^{15}$ yaitu 5 (17\%) dari 30 anak obes yang diteliti di salah satu SMP di Manado dengan kadar kolesterol total abnormal. Hasil yang didapatkan lebih rendah dari yang dilaporkan oleh Tangkilisan et al. ${ }^{16}$ yaitu terdapat $28 \%$ siswa SMP obes dengan kadar kolesterol total abnormal. Kadar kolesterol total yang abnormal (hiperkolesterolemia) yaitu keadaan dengan kadar kolesterol total berada pada nilai yang lebih dari optimal yaitu $\geq 200 \mathrm{mg} / \mathrm{dl}^{17}$

Analisis perbedaan antara kadar kolesterol total pada remaja obesitas dan remaja tidak obes didapatkan nilai $\mathrm{p}<0,05$, yang berarti terdapat perbedaan kadar kolesterol total antara remaja obes dan tidak obes; juga terdapat hubungan kadar kolesterol total dan IMT. Hasil ini berbeda dengan penelitian oleh Rantung et al. ${ }^{15}$ yang tidak menemukan adanya hubungan hiperkolesterolemia pada siswa obes di salah satu SMP di Manado. Hasil pennelitian ini sejalan dengan penelitian yang dilakukan oleh Wulur et al. ${ }^{18}$ yang mendapatkan adanya hubungan antara hiperkolesterolemia dengan gizi berlebih pada anak di Manado.

Pada penelitian ini diperoleh 3 remaja obes $(10 \%)$ yang memiliki kadar trigliserida abnormal. Hasil ini lebih rendah dari hasil penelitian yang didapatkan oleh Iksan et al. ${ }^{7}$ di salah satu SMP di Manado, yaitu $15,4 \%$ siswa obes memiliki kadar trigliserida yang abnormal. Hasil yang sama juga dilaporkan oleh Senduk et al. ${ }^{11}$ yang menemukan $12 \%$ siswa obes di Kota Bitung memiliki kadar trigliserida abnormal. Kadar trigliserida yang abnormal (hipertrigliserida) adalah keadaan kadar trigliserida dalam darah $\geq 150 \mathrm{mg} / \mathrm{dl}$ yang melebihi dari nilai optimal. ${ }^{17}$

Dari hasil analisis perbedaan antara kadar trigliserida pada remaja obes dan remaja tidak obes didapat nilai $\mathrm{p}>0,05$, yang menunjukkan tidak terdapat perbedaan kadar trigliserida antara remaja obes dan tidak obes; juga tidak didapatkan hubungan antara kadar trigliserida dan IMT. Hasil ini berbeda dengan yang didapatkan oleh Valverde et al. ${ }^{19}$ tetapi sejalan dengan yang dilaporkan oleh Ferreira et al. $^{20}$ di Brasil yang tidak menemukan adanya hubungan trigliserida dengan remaja obes.

Walaupun tidak terdapat perbedaan secara statistik kadar trigliserida pada remaja obes dan remaja tidak obes, tetapi didapatkan perbedaan kadar trigliserida dari kedua kelompok remaja tersebut yaitu kadar trigliserida rata-rata remaja obes (95,69 $\mathrm{mg} / \mathrm{dl})$ lebih tinggi dibandingkan remaja tidak obes $(81,45 \mathrm{mg} / \mathrm{dl})$. Selain itu peningkatan kadar trigliserida hanya terjadi pada remaja obes yaitu 3 orang (5\%). Obesitas hanya merupakan salah satu faktor risiko terhadap peningkatan kadar trigliserida walaupun secara statistik tidak ditemukan adanya perbedaan. 
Berdasarkan hasil penelitian, didapatkan 14 remaja obes (48\%) dengan kadar LDL abnormal sedangkan pada remaja tidak obes terdapat 5 remaja $(16 \%)$ yang memiliki kadar LDL abnormal. Hasil yang didapatkan oleh Senduk et al. ${ }^{11}$ pada siswa obes dengan kadar LDL abnormal di Kota Bitung mencapai $82 \%$ dan hasil yang didapatkan oleh Iksan et al. ${ }^{7}$ pada siswa obes di salah satu SMP di Manado dengan kadar LDL abnormal ialah 23,1\%. Yang dimaksudkan dengan kadar LDL abnormal adalah kadar LDL yang lebih dari nilai optimal yaitu $\geq 100 \mathrm{mg} / \mathrm{dl} .{ }^{17}$

Pada hasil uji analisis antara kadar LDL pada remaja obes dan remaja tidak obes didapat nilai $p<0,05$ yang berarti terdapat perbedaan kadar LDL pada remaja obes dan tidak obes serta adanya hubungan antara kadar LDL dan IMT pada remaja. Hasil yang sama juga diperoleh oleh Zamani et al. ${ }^{21}$ yang menemukan adanya hubungan antara LDL dengan IMT, yang berbeda dengan hasil yang ditemukan oleh Ferreira et al. ${ }^{20}$

Berdasarkan hasil penelitian diperoleh 16 remaja obes $(55 \%)$ dan 16 remaja tidak obes $(51 \%)$ memiliki kadar HDL yang abnormal. Hasil yang ditemukan oleh Togelang et al. ${ }^{22}$ pada remaja obes di Kabupaten Minahasa yaitu $100 \%$ memiliki kadar HDL abnormal, sedangkan yang diperoleh oleh Senduk et al. ${ }^{11}$ pada remaja obes di Kota Bitung dengan kadar HDL abnormal ialah $62 \%$. Kadar HDL abnormal adalah kadar HDL yang rendah dengan nilai $<40 \mathrm{mg} / \mathrm{dl} .^{17}$

Hasil uji analisis perbedaan kadar HDL pada remaja obes dan remaja tidak obes diperoleh nilai $\mathrm{p}>0,05$ yang mana tidak terdapat perbedaan kadar HDL antara remaja obes dan remaja tidak obes; juga tidak didapatkan hubungan antara kadar HDL dan IMT pada remaja. Hasil yang berbeda ditemukan oleh Zamani et al. ${ }^{21}$ yang menemukan adanya hubungan kadar HDL dengan IMT pada remaja sedangkan Ferreira et al. ${ }^{20}$ menemukan hasil yang sama dengan penelitian ini.

Secara statistik tidak ditemukan adanya perbedaan kadar HDL pada remaja obes dan remaja tidak obes. Juga didapatkan kadar HDL yang abnormal dengan jumlah yang sama pada remaja obes maupun remaja tidak obes yaitu 16 orang. Walaupun secara teori terjadi penurunan kadar HDL pada obesitas tetapi obesitas bukan merupakan satu-satunya penyebab penurunan kadar HDL. Salah satu faktor lain yang memiliki hubungan dengan penurunan kadar HDL ialah aktivitas fisik. Menurut hasil penelitian, didapatkan adanya hubungan bermakna antara penurunan aktivitas fisik dengan penurunan kadar HDL. ${ }^{23}$ Remaja saat ini cenderung lebih kurang beraktivitas fisik dikarenakan oleh perubahan gaya hidup zaman modern, seperti banyaknya bermain komputer atau menonton TV, kurangnya berjalanan kaki yang diakibatkan oleh bertambahnya jumlah kendaraan. Hal ini yang mungkin menyebabkan tidak terdapat perbedaan kadar HDL pada remaja obes dan tidak obes. ${ }^{7,11}$

Obesitas pada orang dewasa 33\% diperkirakan berasal dari masa kanakkanak dan remaja. ${ }^{24}$ Pada obesitas terjadi perubahan kadar profil lipid yang diakibatkan oleh peningkatan jaringan lemak viseral, yang mana menyebabkan asam lemak bebas yang lebih banyak diarahkan ke hati. Peningkatan asam lemak bebas ke hati ini meningkatkan produksi VLDL yang kaya trigliserida dan apoB sehingga meningkatkan nilai trigliserida dalam darah. VLDL kemudian akan dihidrolisis menjadi IDL yang kemudian akan diubah menjadi LDL yang merupakan lipoprotein dengan jumlah kolesterol terbanyak. Peningkatan kadar LDL akan meningkatkan kadar kolesterol darah yang menyebabkan penurunan kadar HDL yang disebabkan oleh tingginya klirens HDL untuk mengangkut kolesterol darah kembali ke hati. ${ }^{15,17,25}$

Perubahan kadar profil lipid atau dislipidemia ditandai dengan tingginya kadar kolesterol total, LDL, dan trigliserida serta rendahnya kadar HDL yang dapat berisiko menimbulkan kejadian aterosklerosis. Kadar LDL yang tinggi dan HDL yang rendah menyebabkan dinding 
pembuluh darah akan semakin menebal yang menyebabkan terjadinya aterosklerosis. Hal ini dapat meningkatkan risiko penyakit jantung koroner dan stroke iskemik pada remaja obes yang menderita dislipidemia. $^{7,10-12,17,25}$

\section{SIMPULAN}

Berdasarkan hasil penelitian didapatkan bahwa antara remaja obes dan tidak obes terdapat perbedaan bermakna dalam hal kadar kolesterol total dan LDL tetapi tidak terdapat perbedaan bermakna dalam hal kadar trigliserida dan HDL.

\section{SARAN}

Bagi peneliti selanjutnya agar meningkatkan jumlah sampel penelitian agar lebih dapat mewakili populasi.

Untuk para remaja agar mengurangi konsumsi makan yang mengandung tinggi kalori dan lemak seperti burger, pizza, hot dog atau aneka gorengan dan juga memperbanyak aktivitas fisik untuk mengurangi berat badan.

Untuk orang tua agar mengawasi dan membantu anak mengatur pola hidup sehat, juga membawa anak untuk mengontrol kadar profil lipid secara berkala.

\section{DAFTAR PUSTAKA}

1. World Health Organiziation. Childhood overweight and obesity. [cited 2016 Agust 15]. Available from: http://www.who.int/topics/obesity/en/

2. National Institute of Diabetes and Digestive and Kidney Diseases. Overweight and obesity statistics. [cited 2016 Agust 15]. Available from: https://www.niddk.nih.gov/healthinformation/healthstatistics/Pages/overweight-obesitystatistics.aspx

3. World Health Organiziation. Obesity. [cited 2016 Agust 15]. Available from: http://www.who.int/gho/ncd/risk_factors/ obesity_text/en/

4. Kementerian Kesehatan RI. Badan Penelitian dan Pengembangan Kesehatan. Riset Kesehatan Dasar; 2013.

5. Kussoy K, Fatimawali, Kepel B. Prevalensi obesitas pada remaja di Kabupaten Minahasa. eBm. 2013;1(2):981-5.
6. Rafiony A. Konsumsi fast food dan soft drink sebagai faktor resiko obesitas pada remaja SMA di Kota Pontianak (Tesis). Yogyakarta: Universitas Gadjah Mada; 2013.

7. Iksan A, Manampiring A, Fatimawali. Gambaran profil lipid pada siswa obese di SMP Negeri 1 Manado. eBm. 2015;1(1):72-9.

8. Damanik NI, Manampiring A, Fatimawali. Gambaran kadar trigliserida pada remaja obesitas di Kabupaten Minahasa. eBm. 2013;1(1):537-42.

9. Alexander SB. Perbedaan profil lipid pada pasien infark miokard akut dan penyakit pantung non infark miokard akut. Jurnal Media Medika Muda. 2013;2.

10. Holzmann MJ, Jungner I, Walldius G, Ivert $\mathbf{T}$, Nordqvist $\mathbf{T}$, Ostergren $\mathbf{J}$, et al. Dyslipidemia is a strong predictor of myocardial infarction in subjects with chronic kidney disease. Ann Med. 2012;44(3):262-70.

11. Senduk B, Bodhi W, Kepel B. Gambaran profil lipid pada remaja obes di Kota Bitung. eBm. 2016;4(1):122-7.

12. Sugondo. Obesitas. In: Setiati S, Alwi I, Sudoyo A, Simadibrata M, Setiyohadi B, editors. Buku Ajar Ilmu Penyakit Dalam. Jilid II (6th ed). Jakarta: InternaPublishing, 2014; p. 2559-69.

13. Palimbunga D, Pandelaki K, Mongan A, Manoppo F. Perbandingan jumlah trombosit pada pasien diabetes melitus tipe 2 yang menggunakan aspirin dan tidak menggunakan aspirin. eBm. 2013;1(1):202-9.

14. Tuerah W, Manampiring A, Fatimawali. Prevalensi obesitas pada remaja di SMA Kristen Tumou Tou Kota Bitung. eBm. 2014;2(2):514-7.

15. Rantung AA, Umboh A, Mantik $M$. Hubungan hiperkolesterolemia dengan obesitas pada siswa SMP Eben Haezar Manado. eCl. 2014;2(2).

16. Tangkilisan AH, Akune K. Some factors related to lipid profile in obese children at junior high schools in Manado. Paediatrica Indonesiana. 2007;47:166-71.

17. Adam J. Dislipidemia. In: Setiati S, Alwi I, Sudoyo A, Simadibrata M, Setiyohadi B, editors. Buku Ajar Ilmu Penyakit Dalam. Jilid II (6th ed). Jakarta: InternaPublishing, 2014; p. 2549-58.

18. Wulur FH, Pieter RDB. Association 
between serum cholesterol levels and nutritional status in school children aged 10-12 years. Paediatrica Indonesiana. 2003;43:73-6.

19. Valverde MA, Vitolo MR, Patin RV, Escrivão MA, Oliveira FL, AnconaLopez F. Change in lipid profile in obese children and adolescents. Arch Latinoam Nutr. 1999;49(4):338-43.

20. Ferreira LC, Silva HG, Lins TA, Prado WL. Relationship between lipid and hematological profiles with adiposity in obese adolescents. Rev Bras Hematol Hemoter. 2013;35(3):163-6.

21. Zamani A, Beni MA, Abadi M. Relationship between body composition with blood lipid profile. Eur J Exp Bio. 2012;2(5):1509-13.
22. Togelang L, Fatimawali, Manampiring A. Gambaran kadar high density lipoprotein pada remaja obes di Kabupaten Minahasa. eBm. 2013;1:445-50.

23. Gani H, Wongkar D, Ticoalu S. perbandingan kadar kolesterol high density lipoprotein darah pada wanita obes dan non obes. eBm. 2013;1(2):87983.

24. Franca E, Alves JGB. Dyslipidemia among adolescents and children from Pernambuco. Arq Bras Cardiol. 2006;87(6):661-5.

25. Eckel R. Sindrom metabolik. In: Longo D, Fauci A, editors. Harrison Gastroenterologi \& Hepatologi. Jakarta: EGC, 2010; p. 562-8. 